\title{
Globe Based 3D GIS solutions for Virtual Heritage
}

\author{
A. Scianna ${ }^{\text {a }}$ M. La Guardia ${ }^{\text {b }}$ \\ ${ }^{a}$ ICAR-CNR (High Performance Computing and Networking Institute - National Research Council of Italy) at GISLab c/o D'Arch, \\ Polytechnic School of University of Palermo, Viale delle Scienze, Edificio 8, 90128 Palermo, Italy - andrea.scianna@cnr.it \\ ${ }^{b}$ ICAR-CNR (High Performance Computing and Networking Institute - National Research Council of Italy), at GISLab, \\ Via Ugo La Malfa 153, Edificio 8, 90146 Palermo, Italy - marcellolaguardia87@ libero.it
}

Commission IV, WG IV/10

KEY WORDS: Cultural Heritage; WebGIS, WebGL, Globe application, Virtual Reality, Virtual Heritage.

\begin{abstract}
:
During the last years, many solutions have been proposed for 3D Virtual Heritage representations. Recently, also new technologies for online gaming evolved, based on javascript libraries (WebGL), used to create and publish virtual interactive environments. They are based on recent Web browser's functionalities, surpassing some limitations of VRML technologies. On the side of geospatial information, technology has evolved from desktop GIS to 2D WebGIS and globe applications. The use of globe applications is, today, very diffused due to its immediate and at the same time impressive representation of the earth surface and territories. These technologies have been, also, applied to Virtual Heritage 3D reconstructions, to improve the fruition of Cultural Heritage $(\mathrm{CH})$, with the achievement of interesting results. The topic of this paper is the experimentation on the fusion between globe based and gaming technologies (in our case WebGL) that allow achieving a more user-centric and powerful solution useful for publishing 3D geospatial information of $\mathrm{CH}$ on Web. This choice allows obtaining GIS oriented 3D models, typical of globe applications, and, at the same time, a more immersive exploration of $\mathrm{CH}$ and its surrounding environment. In particular, it also gives complementary text and multimedia information on the history, architectural features of each cultural good, based on querying of semantic information. The test field of the research is the construction of the 3D GIS virtual globe model of the Manfredonic Castle of Mussomeli (Sicily-Italy), developed for PON-NEPTIS EU Project, to compare open-source technologies and commercial proprietary applications.
\end{abstract}

\section{INTRODUCTION}

In recent times, new needs of for the dissemination of knowledge on Web have grown up. The new achievements in computer science have allowed people to access online information through tablets and smartphones easily. These needs have become relevant also for $\mathrm{CH}$ sector. At the same time, recent developments of Virtual Reality (VR) applications allowed users to explore environments that, otherwise, would be inaccessible. In fact, the use of Digital Representations (DR) allows creating immersive $3 \mathrm{D}$ models where users can explore different possible past or future reconstructions, impossible to explore in the real world (Eve, 2012; Marques et al 2017). DR also extends the fruition of these environments to disabled people.

For these reasons, the application and development of VR technologies for the creation of 3D $\mathrm{CH}$ representations and virtual reconstructions is a fundamental research field. It's also of great importance the extension of these techniques to allow the functions of $\mathrm{CH}$ on mobile devices. From the merger of VR and CH comes the term Virtual Heritage (VH) (Roussou, 2002). The virtualisation of heritage consists of the digitalisation of the $\mathrm{CH}$ to simulate and recreate it with the help of computer graphic technology (Tan et Rahaman, 2009).

Furthermore, the recent development in advanced survey technologies, LIDAR (laser scanning) and photogrammetry, has given the possibility to make $3 \mathrm{D} \mathrm{CH}$ reconstruction easier and with a better level of accuracy than before (Dore et Murphy, 2012). A strong contribution in this sense has been given by rapid 3D photogrammetry restitution methods, such as Structure For Motion (SFM), that recreates a probabilistic distribution of the structure through an iteration step by step (Dellaert et al. 1999).
Indeed, virtual environment representations allow scholars, tourists and other stakeholders to visit cities, monuments, places that would be inaccessible in reality (for example virtual tours in impervious places or past configurations of $\mathrm{CH}$ ). Besides, a VH representation, where a Cultural Good appears inserted into surrounding environments, helps to discover the relationship between the $\mathrm{CH}$ and the landscape around it. For example, some applications achieved the possibility, in archaeological sites, of overlapping the virtual reconstruction of the past configuration of a Cultural Good over the real one or showing findings in places where they were discovered (this is the case of augmented reality applications, which depends on the virtual 3D reconstruction).

It's necessary to add a further level of information to simple virtual reality representations, to achieve an exhaustive level of user's involvement. For this reason, the recent progress in geographic information field allows the implementation of Geographic Information System (GIS) technologies into virtual reality applications, enabling the construction of immersive virtual environments (Valencia et al., 2015). In fact, the addition to semantic and geographic information, linked to virtual reality representation, gives a fundamental added value to the virtual exploration experience. With this goal, Globe applications (e.g. Google Earth) are born, allowing a virtual representation of the whole earth, where users can load different levels of information and 3D models positioned on the surface of the globe, according to their geographical coordinates. Given all this, the possibility of adding information on buildings and landscapes to virtual experience leads users to become more involved during navigation.

The main specific goal of the research here illustrated is the merging of WebGL technologies (for virtual reality representation on Web) and Globe applications (for the addition 
of geographic information to $3 \mathrm{D}$ models), to create an exhaustive more immersive $\mathrm{VH} 3 \mathrm{D}$ geospatial information system.

\section{THE USE OF WEBGL TECHNOLOGIES FOR THE CREATION OF ONLINE VIRTUAL ENVIRONMENTS.}

In recent times, advances in Information and Communication Technology (ICT), in particular on VR, have allowed the creation of 3D $\mathrm{CH}$ environments for interactive navigation on Web (Guarnieri et al., 2010). For example, many studies have been carried out, where cloud computing tools and usergenerated content were integrated into an online cultural environment (Dellepiane et al., 2011). In this contest, since 2007, new VR technologies like WebGL, a Web-based opensource graphics library for Web-browsers (OpenGL based), started to allow the creation of 3D navigation systems of virtual environments on Web. This solution gives the possibility of generating virtual textured environments creating different navigation modes. The development of WebGL technologies allows users to navigate on Web, inside 3D environments, in an interactive way, without the requirement of any additional app or plugin. The WebGL choice represents a very user-friendly and human-centred solution, also because WebGL models can be accessible from every kind of device (smartphones, tablets, PCs) only accessing the Web site. Today this is only possible for updated devices with latest versions of operating systems and Web browsers. In fact, WebGL technology is now implemented inside many diffused browsers (Chrome, Firefox and Safari). The loading capabilities of 3D WebGL environments are managed only on server-side, but the management and navigation are charged on client-side, once the $3 \mathrm{D}$ environment is loaded on it.

This technology, originally used for experimentations of simple virtual environments or primitive gaming experiences, now represents a serious solution for the construction of complex virtual environments accessible online. In particular, in the last few years, this way has also been experimented for $\mathrm{VH}$ reconstructions, with interesting results. The first experiments were carried out for the virtual reconstruction of statues and archaeological finds. This solution has been very useful for sharing online the information regarding contents of museums (Pescarin, 2014), and was interesting enough, but did not take full advantage of the WebGL technologies potential, that has evolved over the last few years. In fact, these technologies give the possibility not only to visualise virtual 3D model on Web but also to recreate virtual complex $3 \mathrm{D}$ environments and to navigate inside them, also obtaining additional context-aware information. The addition of context information is a fundamental feature for $\mathrm{VH}$ representation because archaeological sites and monuments are ever strongly connected with the surrounding natural or urban environments. For this reason, recently, WebGL solutions have also been refined for representation and reconstruction of virtual archaeological sites (Scianna et al. 2016a) or their parts, such as ancient theatres (Scianna et al. 2016b), also allowing an interactive online exploration of $\mathrm{CH}$ in the past. However, there are also some limitations on the size of the 3D model to be visualised, because most browsers crash if the dataset to download is too big. For this reason, the recent research is focused on obtaining the best immersive and realistic 3D experience with smaller 3D models characterized by the less number of polygons to download from the servers (the quality of the texture plays a key role). The experimented 3D objects are modelled by surfaces, using 3D meshes. To obtain a model that fits visualisation need, ensuring the most appropriate Level of Detail (LoD) and good visualisation quality, is fundamental to find the right balance between the level of simplification of meshes and the quality of texture applied on them. Besides, using WebGL libraries is also possible to experiment with different navigation modes, which could be opportunely chosen and programmed depending on the devices (PCs, tablets and smartphones) to be used. WebGL technologies, hence, represents an important and constantly evolving solution useful for 3D VH representation.

\section{THE DEVELOPMENT OF GLOBE VIRTUAL ENVIRONMENTS IN GEOMATICS.}

In the past, the access to georeferenced data, linked with semantic information databases, was guaranteed only for specialised users (engineers, architects, archaeologists, etc..) using GIS desktop software. The next level of development has been achieved with the creation of WebGIS applications, which allowed users a 2D GIS online navigation, with the possibility of querying information and successively loading remote layers (disseminated in Internet servers) using Web Map Services (WMS) and Web Feature Services (WFS). The big diffusion of geospatial data for every target of users took place with the creation of virtual representations of the earth (Virtual Globes), where the simple and user-friendly interface has played a key role.

Recent advances in ICT technologies allowed the development of new, well performing, Globe applications, which are real human-centred GIS solutions. Between these, Google Earth, the most famous free 3D globe application, helped the diffusion of the knowledge on geomatics and earth geospatial data all over the world. After Google Earth, many other similar open-source and commercial proprietary applications have been developed, with different solutions and technologies.

There are several possibilities of interaction, given by virtual Globes, characterised by the user-friendly interface in data collection and visualisation, differently from traditional 2D GIS (Yu et Gong, 2012). In fact, the virtual Globe choice provides a multi-dimensional GIS, based on a 3D virtual globe representation with the addition of the digital terrain model (DTM), that consists on the digital representation of the earth's surface on the ground (Pirotti et al., 2017). This technology offers a very user-friendly solution because the 3D terrain representation inserted into a geographic information system allows direct and simple access to information and the comprehension of the geomorphology of the territory. Besides, in recent times these Globe models can be integrated with the insertion of 3D city models (with buildings, roads, bridges etc..) and layers, downloaded through WMS services, draped over the DTM surface.

The integration of 3D city models into Web-based virtual Globes, necessary for interactive visualisation of the 3D urban environment, remains a hard challenge due to the data size of models. In fact, big data visualisation usually overload the computational power (Nquyen et al., 2016). Anyway, the future development and implementation of 3D GIS applications are certainly based also on Globe solutions.

\section{THE EXPERIMENTATION OF DIFFERENT SOLUTIONS ON 3D VIRTUAL HERITAGE INTERACTIVE NAVIGATION MODELS INSIDE GLOBE APPLICATIONS}

In light of what discussed before, the solutions presented in this paper show different options of 3D VH models created merging Web technologies, gaming technologies and GIS Globe applications, to build a better human-centred solution for VH. In this experimentation, the Medieval Castle of Mussomeli, in Sicily (Italy) has been used as a study case. 
This monumental complex was built in 1374 (with a height of about $100 \mathrm{~m}$ above the ground level of neighbouring land), on a massive rock that dominates the surrounding territory for many kilometres.

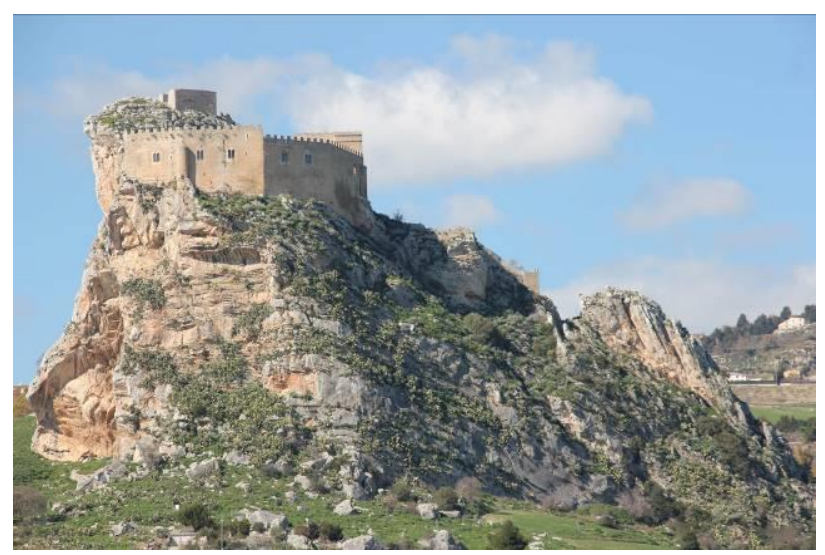

Figure 1. The Medieval Castle of Mussomeli (Sicily)

The construction of 3D model and navigation system have been carried out following a complex workflow. The survey has been carried out using Unmanned Aerial Vehicle (UAV) technologies to acquire aerial images and Global Navigation Satellite System (GNSS) receivers for GCP survey. In particular, it's been created a network of 24 visible targets distributed along the climbing path. The flight has been operated using a DJI Matrice 100 quadcopter, equipped with a Zenmuse X3 camera with a resolution of 12 Megapixels.

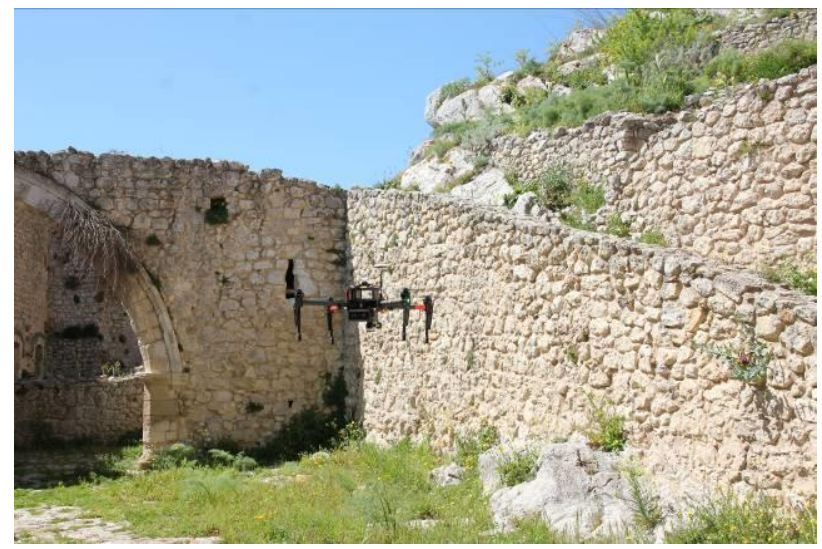

Figure 2. The survey operation of the castle with UAV

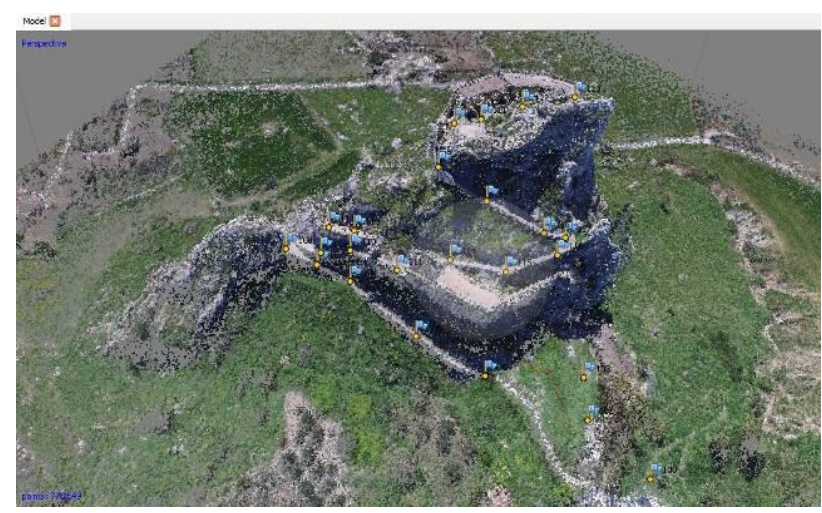

Figure 3. The sparse cloud reconstruction with the indication of the GCP

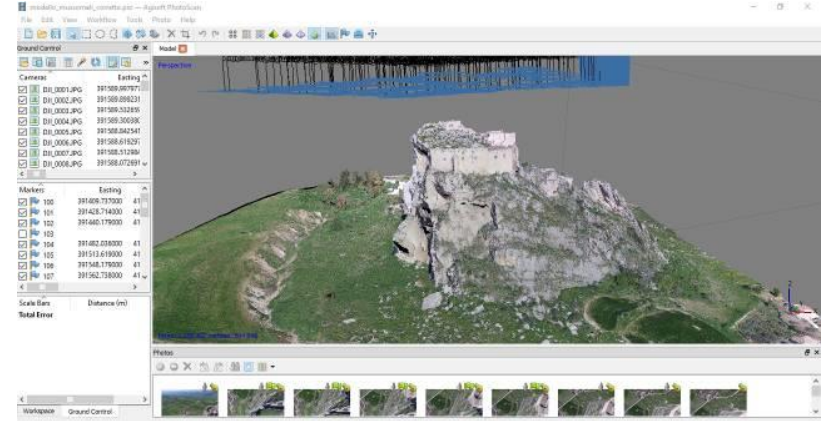

Figure 4. The 3D model of the castle obtained from the photogrammetric reconstruction

The next step has been the photogrammetric reconstruction of the point cloud of the castle and the surrounding environment, using Agisoft Photoscan, an application based on Structure For Motion (SfM). Then, the textured 3D mesh of the model has been extracted from the point cloud.

The structure of the castle was complex. For this reason, not only the outdoor environment has been reconstructed but also the main rooms and the main courtyard, to offer a more exhaustive possibility of exploration inside the castle. These indoor environments have been surveyed shooting pictures for every room from different angles and different points of view, obtaining a rapid, but at the same time exhaustive photogrammetric reconstruction of the rooms for virtual navigation. On this phase has been used an SLR Camera, Canon EOS 550D, with a resolution of 18 Megapixels. As for the outdoor reconstruction, the 3D meshes of indoor environments have been obtained from the point cloud, generated by SfM procedures.

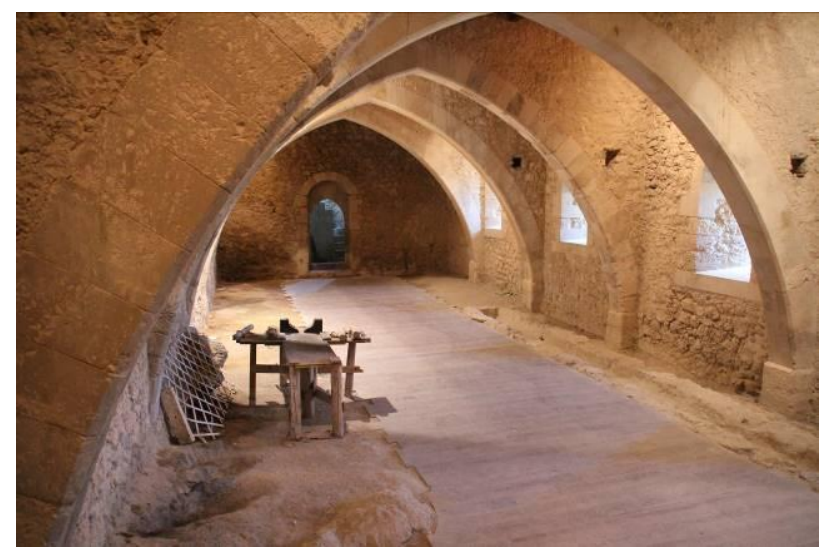

Figure 5. One of the main indoor environments of the castle

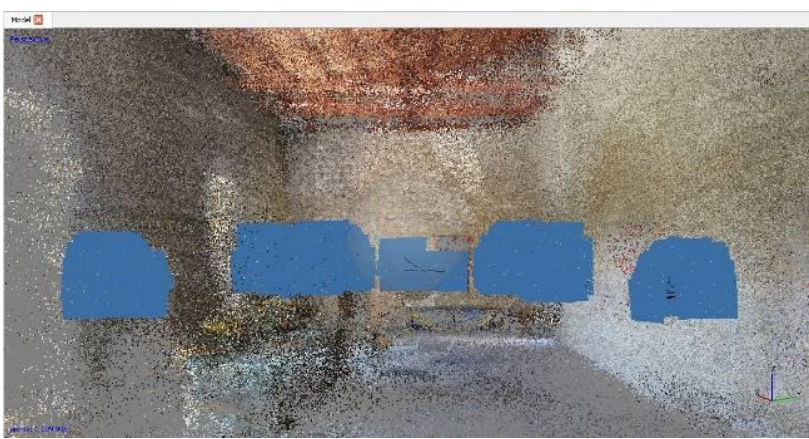

Figure 6. An example of a sparse cloud reconstruction of an indoor environment of the castle 


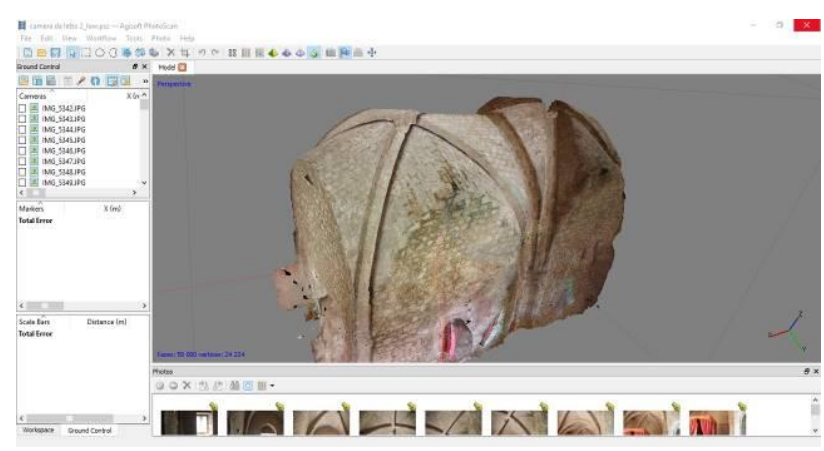

Figure 7. An example of a 3D model of an indoor environment of the castle obtained from the photogrammetric reconstruction

Once obtained the textured 3D model of the monumental complex, on indoor and outdoor environments, the experimentation has been split to study different solutions of VH interactive navigation models. Considering every possible way to follow for the creation of the navigable model, all the studied solution needed a preliminary operation of deep simplification of the original mesh because the original model obtained from the photogrammetric reconstruction weighted more than $100 \mathrm{Mb}$.

For this reason, it has been necessary a decimation process of meshes, saving the texture resolution anyway, to preserve the virtual perception of the model. The final 3D models considered for the interactive navigation on Web weighted 10-20 Mb. This size resulted fully compliant in avoiding the overloading problems that affect Web client visualisation.

Once 3D models were obtained, experimentation was continued with testing different solutions of 3D $\mathrm{VH}$ interactive navigation models. In particular, an open-source solution has been developed, based on WebGL libraries, which has been compared with another similar solution developed using a commercial proprietary software.

\subsection{The studied free and open-source solution for a VH fruition on Web.}

The solution carried out for merging gaming technology, and virtual Globe applications is the result of the combination between the experimentation previously carried out (Scianna et al., 2016a, Scianna et. al, 2016b, Scianna et La Guardia, 2017) and the last opportunities offered from last updates of WebGL libraries. In particular, a virtual navigation model based on Cesium ${ }^{\circledR}$ has been developed (a Web-based Globe model built on WebGL libraries). Cesium open-source libraries allow to insert DTM terrain models, 3D models, maps, and shapefiles modifying the main HTML template page, using javascript strings. This solution is HTML5 compliant and, as every model developed with WebGL libraries, is navigable using most diffused browsers (Chrome, Firefox, Safari).

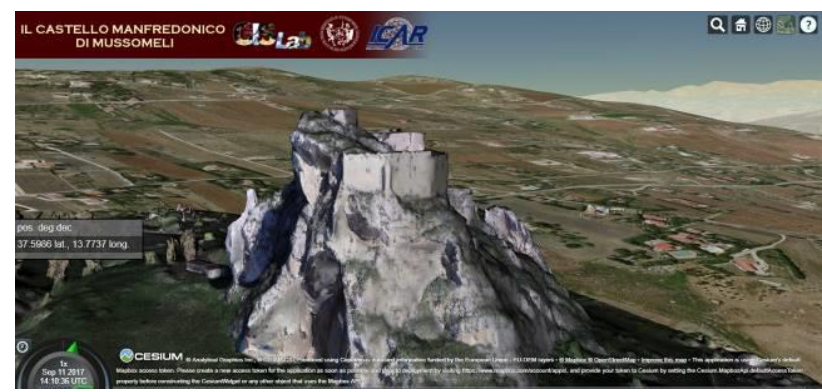

Figure 8 . The virtual navigation in the model generated with the open-source solution

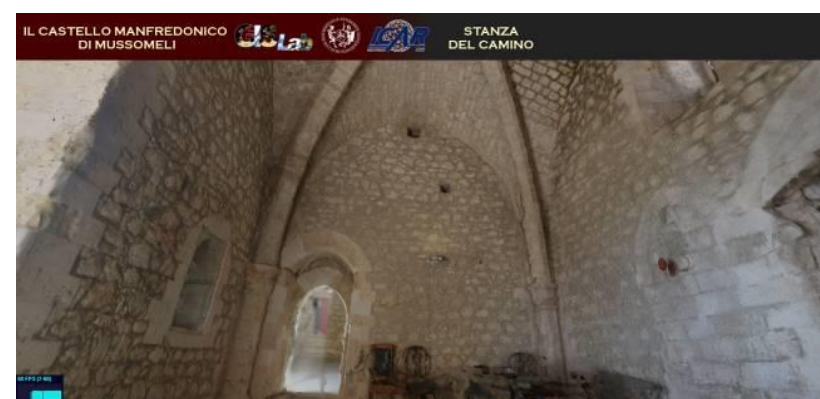

Figure 9. The virtual indoor navigation inside the model of the castle generated with the open-source solution

The workflow regarding the construction of the virtual environment, using open-source solution, was articulated as follow:

- uploading of Cesium.js libraries into the server folder, to activate the globe default model;

- implementation of the main .html template into the server folder, loading the 3D model of the castle, and positioning it in the correct georeferred place inside the globe;

- modification of the main .html template, to create a set of queryable elements, located in the castle, in correspondence with the rooms to explore;

- creation of linking queryable elements containing a semantic description with the activation of "on click" query windows. Every window has been implemented with an image, a description of the room, and a link to the $3 \mathrm{D}$ interactive visualisation;

- insertion of an additional window on the interface for every clicked element on the globe, with the indication of the coordinates of clicked points.

Once developed the interactive visualisation of the main model, every $3 \mathrm{D}$ model of rooms has been inserted into the navigation system. For each one of these, a navigation 3D environment using a.$h t m l$ template page linked with Three.js libraries (javascript libraries based on WebGL) has been built and the 3D textured model of the corresponding environment has been loaded on every template.

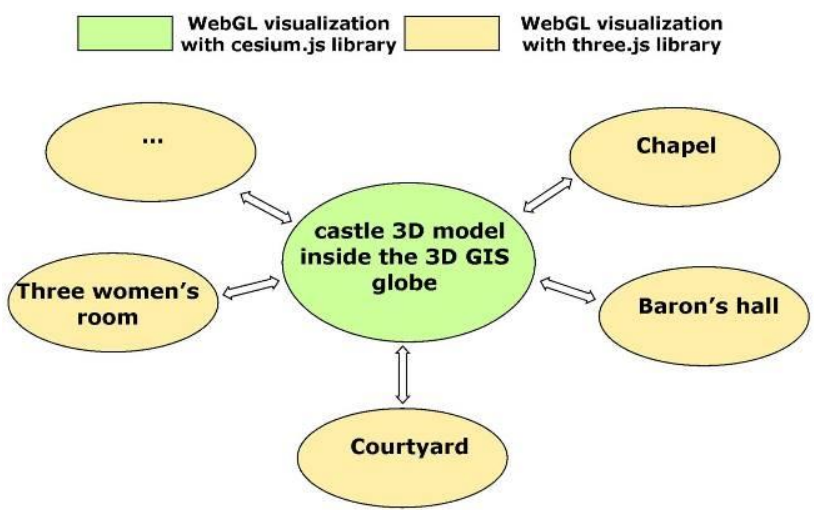

Figure 10. The structure of the open-source WebGL-based solution

Therefore, a hierarchic system has been created, where the main .html page (based on Cesium.js libraries and inclusive of the globe 3D model and the main 3D model of the castle) has been linked with the secondary .html pages (based on Three.js libraries and inclusive of main rooms of the monumental complex). 


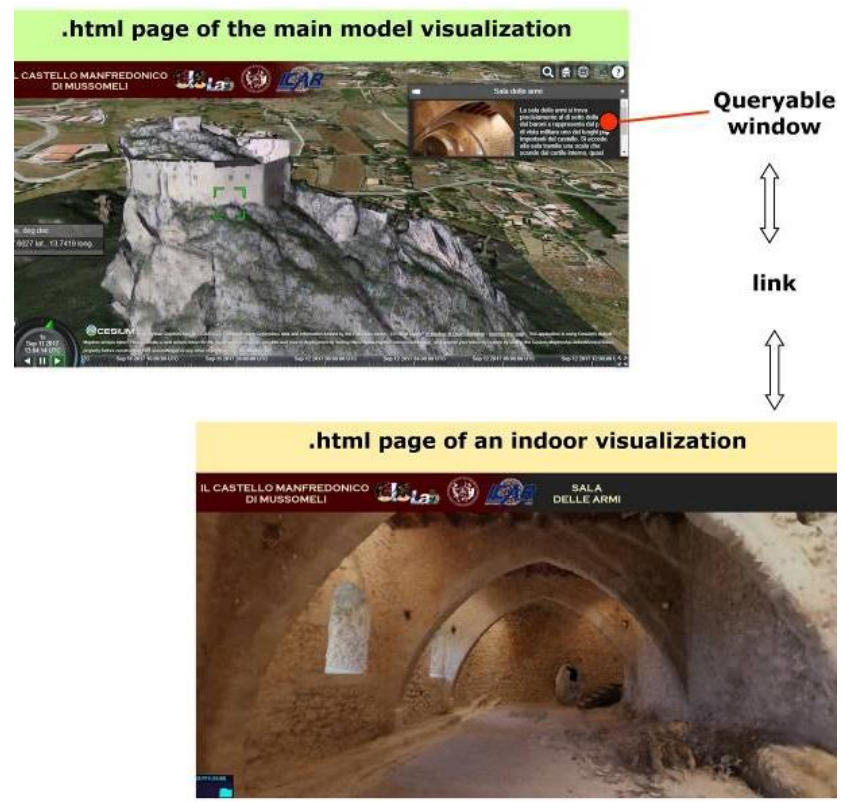

Figure 11. The link function between main 3D model and an indoor environment

Finally, the realised system consists in a VH 3D GIS navigation model, accessible from most diffused browsers connecting to an internet address (compliant with HTML5) and built using opensource technology based on WebGL (Cesium.js and Three.js libraries). The system can also support WMS and WFS services, with the possibility of loading layers and base maps on the virtual model, connecting with remote geographic servers.
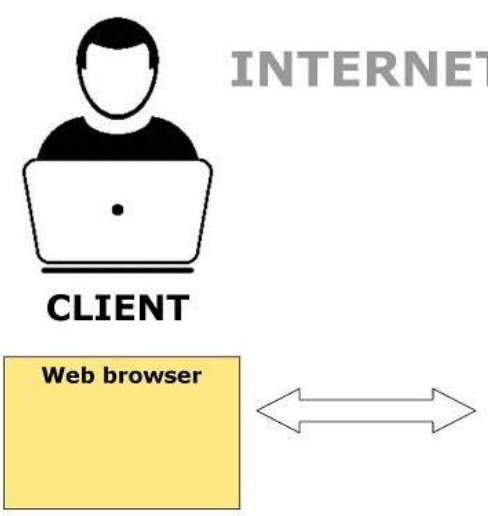
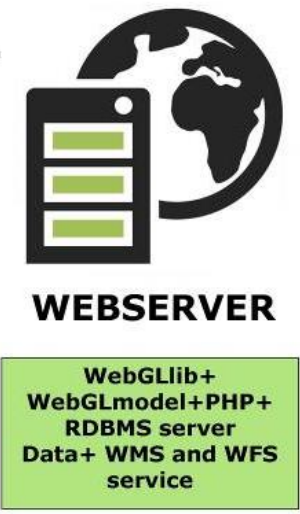

Figure 12. The connection between client-side and server-side chosen for the open-source solution

4.2. The comparison between the studied open-source solution for a VH fruition on Web and a commercial one.

The open-source solution for a VH fruition on Web has been compared with another solution developed using Skyline Terra Explorer ${ }^{\circledR}$, commercial proprietary software for the development of 3D GIS environments. The interface of Terra Explorer allows to easily import maps, shapefiles, and 3D models inside a 3D virtual Globe in a simple way.

This software also presents a free version that allows only the visualisation of created environments.

The workflow followed for the construction of the virtual environment with Terra Explorer has been divided into these steps:
- the 3D simplified model of the castle and indoor models have been loaded into the virtual globe. Unlike the WebGL solution, where the insertion of 3D models of different formats was allowed, the commercial proprietary solution allows to load only dae format, exported from Google Sketchup or Photoscan commercial proprietary software;

- the indoor environments have been inserted inside the same globe model, merging all of the rooms with the main model of the castle and inserting them in the correct position;

- once created the total model of the castle, a system of georeferred transparent elements has been developed in correspondence with the specific environments to describe, creating popup windows containing relative information.

Once the 3D model of the castle has been inserted into the local globe interface, the system has been exported, creating a folder with an external server address. The system configuration allows everyone to install the free version of Terra Explorer, and loading of the model, connecting to the server folder and using the navigation interface of the software.

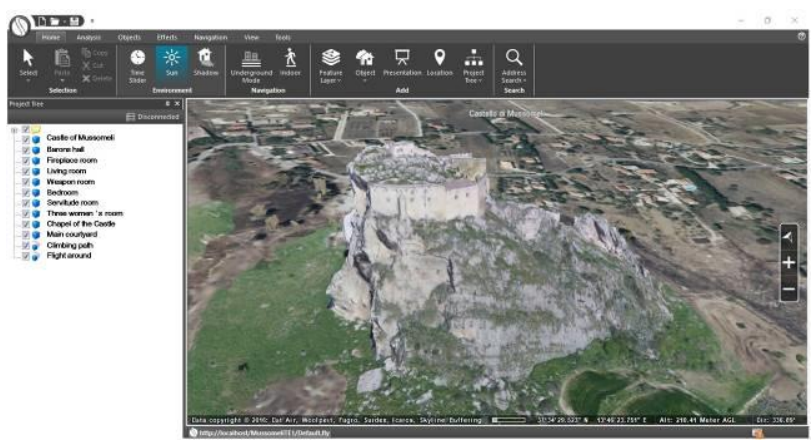

Figure 13. The virtual navigation in the model generated with the commercial proprietary solution

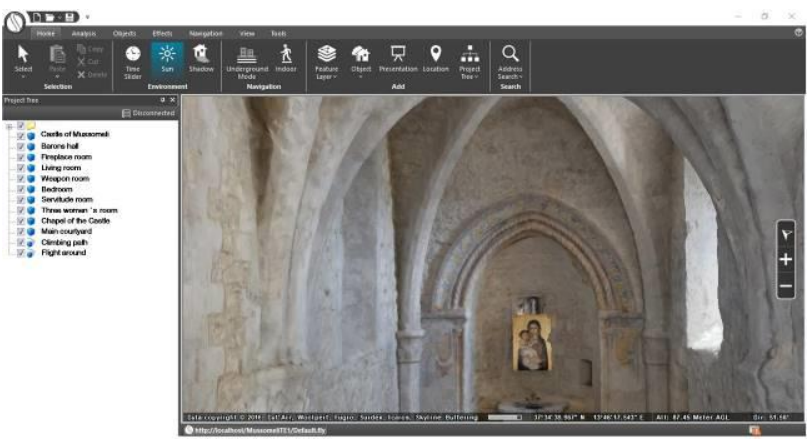

Figure 14. An indoor environment accessed through the commercial proprietary solution interface

\section{CONCLUSIONS AND OPEN SCENARIOS.}

In light of the studied case, it's possible to focus the differences and ascertain strengths and weaknesses of both solutions, considering the free and open-source solution and the commercial proprietary one.

In particular:

- the exploration possibilities on the main model are similar, both of the interfaces allow to freely navigate around the castle, with a system of pop-up information windows;

- the open-source solution allows users to access to the virtual environment without installing any app, only connecting to the Web page using the most common browsers (Chrome, Firefox, Safari). Differently, the commercial solution allows the access to the navigating system only installing the free version of the browsing software, and connecting to the model's address; 
- the speed of access depends on the different experimented technologies. In particular, in the open-source solution, slowdowns can be caused from the loading time of 3D models, that mainly depends, not only on the hardware features of the client device but also on the speed and the number of packets sent, in sequence, by the server. Instead, the commercial proprietary solution sometimes presents some difficulties regarding the loading of textures due to the size of 3D models;

- the indoor environments of the open-source solution are located each one in a separated Web page and opportunely connected by links to the main environment. Instead, the commercial solution contains the entire model inside the same visualisation.

- both of the solutions work in a georeferred space, and allow the connection with WMS service, with the possibilities of implementation of raster and vector data connected with external databases.

- The opensource choice based on Cesium libraries allows loading 3D models into the Globe starting from .dae or .obj files, which represents the most common extensions for 3D models, available for opensource and commercial proprietary software. Instead, the commercial proprietary solution based on Terra Explorer seems to be very rigid for the choice of 3D format, because, as seen before, it accepts only dae files created with some proprietary software.

\begin{tabular}{|l|l|l|}
\hline $\begin{array}{c}\text { FEATURES } \\
\text { (Highlights and Issues) }\end{array}$ & $\begin{array}{c}\text { OPEN SOURCE } \\
\text { (WebGL) }\end{array}$ & $\begin{array}{c}\text { COMMERCIAL PROPRIET ARY } \\
\text { (TERRA EXPLORER) }\end{array}$ \\
\hline $\begin{array}{l}\text { Free navigation around } \\
\text { the model }\end{array}$ & \\
\hline $\begin{array}{l}\text { System of popup } \\
\text { Information windows }\end{array}$ & \\
\hline $\begin{array}{l}\text { Indoor and outdoor } \\
\text { environments in the } \\
\text { same visualization }\end{array}$ & \\
\hline $\begin{array}{l}\text { Possible WMS data } \\
\text { implementation }\end{array}$ & \\
\hline $\begin{array}{l}\text { Possibilities of crashes } \\
\text { or partial loadings }\end{array}$ & \\
\hline $\begin{array}{l}\text { Difficoulties of loading } \\
\text { oversized textures }\end{array}$ & \\
\hline $\begin{array}{l}\text { Software installation } \\
\text { required }\end{array}$ & \\
\hline $\begin{array}{l}\text { Rigid limitations on 3D } \\
\text { model format files }\end{array}$ & \\
\hline
\end{tabular}

Figure 15. strengths and weaknesses of open-source and commercial proprietary solutions

To conclude, it's possible to affirm that the result obtained from the commercial software is not far from that obtained with open-source technology. The construction of the 3D GIS virtual environment is simpler using the commercial software because the development of the model takes place via an interface, and no specific experience on programming is required, so that allows a faster development. Instead, considering the user needs, probably the open-source solution is more direct because no installation of any app is required. Both of the solutions represent some limitations about the dimensions of 3D models because the possibilities of visualisation crashes or loading issues are strongly linked to the increment of the number of polygons. Anyway, the Globe-based studied solutions are 3D GIS VH experimentations that work online and could be considered an important step for the research on publishing $\mathrm{CH}$ information on Web. Hence, the possibilities of implementing different kinds of data (3D models, orthophotos, WMS services, DEM) in a unique georeferred model available online, open new scenarios for the sharing of $\mathrm{CH}$ information and documentation on Web. The studied solutions of this work are available and navigable online connecting to GISLab Website at the address http://gislab.dirap.unipa.it/mussomeli/ .

\section{REFERENCES}

Dellaert, F., Seitz, S.M., Thorpe, C.E., Thrun, S., 1999. Structure from Motion without Correspondence. Dissertation, Carnegie Mellon University.

Dore, C., Murphy, M., 2012. Integration of HBIM and 3D GIS for Digital Heritage Modelling. In: Virtual Systems and Multimedia (VSMM), 2012 18th International Conference, Edimburg, Scotland: IEEE, 22-23.

Eve, S., 2012. Augmenting Phenomenology: Using Augmented Reality to Aid Archaeological Phenomenology in the Landscape. Journal of Archaeological Method and Theory, 4 (6), 582-600.

Guarnieri, A., Pirotti, F., Vettore, A., 2010. Cultural heritage interactive 3D models on the Web: An approach using open source and free software. Journal of Cultural Heritage, 11, 350353.

Lercari, N., Toffalori, E., Spigarolo, M., Onsurez, L., 2011. Virtual Heritage in the Cloud: New Persectives for the Virtual Museum of Bologna. In: M. Dellepiane, F. Niccolucci, S. Perna Serna, H. Rushmeier, L. Van Gool, ed. The 12th International Symposium on Virtual Reality, Archaeology and Cultural Heritage VAST, The Eurographics Association, 153-160.

Marques, L., Tenedorio, J.A., Buns, M., Romao, T., Birra, F., Marques, J., Pires, A., 2017. Cultural Heritage 3d Modelling and visualisation within an Augmented Reality Environment, based on Geographic Information Technologies and mobile platforms. ACE: Architecture, City and Environment, 11 (33), 117-136.

Nguyen, Q.D., Bredif, M., Richard, D., Paparotidis, N., 2016. Progressive streaming and massive rendering of 3D city models on Web-based virtual globe. In: Proceedings of the 24th ACM SIGSPATIAL International Conference on Advances in Geographic Information Systems, Burlingame, California, 83.

Pescarin, S., 2014. Museums and Virtual Museums in Europe: Reaching expectation. SCIentific RESearch and Information Technology, 4 (4), 131-140.

Pirotti, F., Brovelli, M.A., Prestifilippo, G., Zamboni, G., Kilsedar, C.E., Piragnolo, M., Hogan, P., 2017. An open source virtual globe rendering engine for 3D applications: NASA World Wind. Open Geospatial Data, Software and Standards, 2(4), 1-14.

Roussou, M., 2002. Virtual Heritage: From the Research Lab to the Broad Public. In: F. Niccolucci, ed. Virtual Archaeology. BAR International Series, 93-100.

Scianna, A., La Guardia, M., 2017. Main Features of a 3D GIS for a Monumental Complex with an Historical-Cultural Relevance. In: ISPRS - International Archives of the Potogrammetry, Remote Sensing and Spatial Information Sciences - GEOMATICS AND RESTORATION - Conservation of Cultural Heritage in the Digital Era, Florence, Italy, XLII5/W1, 519-526. 
Scianna, A., La Guardia, M., Scaduto, M.L., 2016. Definition of a Workflow for Web Browsing of 3D Models in Archaeology. In: M. Ioannides, E. Fink, A. Moropoulou, M. Hagedorn-Saupe, A. Fresa, G. Liestol, V. Rajcic, P. Grussenmeyer ed. Digital Heritage. Progress in Cultural Heritage: Documentation, Preservation, and Protection. 6th International Conference, Euromed 2016, Nicosia, Cyprus, Part II, 41-52.

Scianna, A., La Guardia, M., Scaduto, M.L., 2016. Sharing on Web 3D Models of Ancient Theatres. A Methodological Workflow. In: ISPRS - International Archives of the Potogrammetry, Remote Sensing and Spatial Information Sciences - XXIII ISPRS Congress, Prague, Czech Republic, XLI-B2, 483-490.

Tan, B.K., Rahaman, H., 2009. Virtual Heritage: Reality and Criticism. In: T. Tidafi and T. Dorta, ed. Joining Language, Cultures and Visions: CAADFutures 2009. 143-156.

Valencia, J., Munoz-Nieto, A., Rodriguez-Gonzalvez, P., 2015. Virtual modeling for cities of the future. State-of-the art and virtual modeling for cities of the future. State-of-the art an. In: ISPRS - International Archives of the Photogrammetry, Remote Sensing and Spatial Information Sciences - 3D Virtual Reconstruction and Visualization of Complex Architectures, Avila, Spain, XL-5/W4 (18), 179-185.

Yu, L., Gong, P., 2012. Google Earth as a virtual globe tool for Earth science applications at the global scale: progress and perspectives. International Journal of Remote Sensing, 33 (12), 3966-3986. 